\title{
AVALIAÇÃO DA RESISTENCIA A CORROSÃO DE AÇOS ALTO MANGANÊS E O AÇO $9 \%$ NÍQUEL EM SOLUÇÃO DE $\mathrm{NaCl}^{*}$
}

\section{Resumo}

\author{
Marcos Natan da Silva Lima ${ }^{1}$ \\ Mauro Andrés Cerra Flórez ${ }^{2}$ \\ Pedro Paulo Nunes Maia ${ }^{3}$ \\ Walney Silva Araújo ${ }^{4}$ \\ Hamilton Ferreira Gomes de Abreu ${ }^{5}$
}

O presente estudo tem como objetivo avaliar a resistência à corrosão de dois aços alto teor de Manganês com relação à liga $9 \%$ Níquel em solução eletrólito $0,001 \mathrm{M}$ de $\mathrm{NaCl}$. Para esta pesquisa foram utilizados dois aços com teores de Manganês de $22 \%, 27 \%$ e uma liga $9 \%$ Níquel que é amplamente utilizada na indústria petroquímica. Os ensaios realizados para comparação da resistência à corrosão foram o monitoramento do potencial de circuito aberto (OCP) e polarização linear anódica. Foi escolhida a solução de $\mathrm{NaCl}$ pela presença da maioria dos tanques de armazenamento e transporte de gás natural se localizarem próximos à região marítima portuária. Foram utilizadas as técnicas de Microscopia Eletrônica de Varredura (MEV), Microscopia óptica e Espectroscopia de Energia Dispersiva de Raios-X (EDS) para a caracterização dos produtos de corrosão. Os resultados obtidos mostraram que os aços alto Manganês apresentaram valores similares de resistência à corrosão, mas ainda inferiores em relação ao aço $9 \%$ Níquel.

Palavras-chave:Corrosão; Aço Alto Manganês; Aço 9\% Níquel, Gás Natural.

\section{EVALUATION OF CORROSION RESISTANCE OF HIGH MANGANESE STEELS AND 9\% NICKEL STEEL IN SOLUTION OF NaCl.}

\section{Abstract}

The present study aims to evaluate the corrosion resistance of two high manganese steels with respect to the $9 \%$ Nickel steel in $0.001 \mathrm{M} \mathrm{NaCl}$ electrolyte solution. For this research, two steels with $22 \%, 27 \%$ manganese were used, and the alloy of $9 \%$ Nickel which is widely used in the petrochemical industry. The tests carried out to compare the corrosion resistance were the open circuit potential (OCP) and anodic linear polarization. The $\mathrm{NaCl}$ solution was chosen because most of the natural gas storage and transport tanks were located near the port maritime region. The techniques of Scanning Electron Microscopy (SEM), Optical Microscopy and X-ray Dispersive Energy Spectroscopy (EDS) were used to characterize the corrosion products. The results showed that high manganese steels presented similar values of corrosion resistance, but still lower than $9 \%$ nickel steel.

Keywords: Corrosion; High Manganese Steel; 9\% Nickel Steel, Natural Gas.

1 Mestrando em Engenharia e Ciência de Materiais, Engenheiro Metalúrgico e de Materiais, Bolsista, Departamento de Engenharia Metalúrgica e de Materiais, Universidade Federal do Ceará (UFC), Fortaleza, Ceará, Brasil.

2 Mestrando em Engenharia e Ciência de Materiais, Engenheiro Metalúrgico, Bolsista, Departamento de Engenharia Metalúrgica e de Materiais, Universidade Federal do Ceará (UFC), Fortaleza, Ceará, Brasil.

3 Estudante de Engenharia Metalúrgica, Bolsista, Departamento de Engenharia Metalúrgica e de Materiais, Universidade Federal do Ceará (UFC), Fortaleza, Ceará, Brasil.

4 Doutor em Engenharia Metalúrgica, Engenheiro Químico, Docente, Departamento de Engenharia Metalúrgica e de Materiais, Universidade Federal do Ceará (UFC), Fortaleza, Ceará, Brasil.

5 Doutor em Engenharia Metalúrgica e de Materiais, Engenheiro Nuclear, Docente, Departamento de Engenharia Metalúrgica e de Materiais, Universidade Federal do Ceará (UFC), Fortaleza, Ceará, Brasil. 


\section{INTRODUÇÃO}

O aço manganês austenítico original, contendo cerca de 1,2\% Carbono e 12\% Manganês, foi criado por Sir Robert Hadfield, em 1882. Foi uma descoberta que conseguiu conciliar alta tenacidade, ductilidade com alta capacidade de endurecimento em trabalho e boa resistência ao desgaste (1). Os aços Hadfield (aço Manganês austenítico) ainda são amplamente utilizados, com pequenas modificações na composição e tratamento térmico, principalmente nas áreas de terraplenagem, minas e pedreiras, bem como perfuração de petróleo, siderurgia e dragagem. (2; 3).

Muitas variações do aço austenítico manganês original que têm sido propostas nos últimos anos, geralmente envolvendo variações de carbono e de manganês, com ou sem elementos de liga. Outro grande estudo de aplicação das novas ligas de aço alto manganês tem sido para aplicações criogênicas como material de transporte e armazenagem de GNL (Gás Natural Liquefeito), onde se busca propriedades mecânicas de elevadas resistência e tenacidade à baixíssima temperatura (criogênica) (4).

O gás natural em temperaturas criogênicas sofre uma drástica redução em seu volume, facilitando sua armazenagem e transporte. De uma forma geral, as ligas utilizadas para fabricação de tanques de GNL necessitam de alta resistência para que a espessura da parede do tanque seja minimizada, e se faz necessário também que essas ligas apresentem alta tenacidade em baixas temperaturas. Entre essas ligas está o aço $9 \% \mathrm{Ni}$, principal aço utilizado para essa aplicação. Os aços alto Manganês surgiram como alternativa e devido ao seu menor custo em relação ao aço $9 \%$ Níquel, onde o Mn substitui o Ni como elemento estabilizador da austenita, fase imprescindível para manutenção das propriedades necessárias a baixas temperaturas. Há muitos estudos realizados sobre os aços alto $\mathrm{Mn}$, onde principalmente são avaliadas às propriedades mecânicas, porém menos ou quase nenhuma atenção tem sido dada a resistência à corrosão desses novos aços com altos teores de Mn. Neste trabalho foram utilizadas três composições do aço alto Manganês e o aço $9 \%$ Níquel, com os quais foram realizados ensaios de corrosão para comparar o comportamento das ligas em solução aquosa de $\mathrm{NaCl}$, simulando o ataque corrosivo de correntes marítimas presentes nos campos de armazenamento e transporte do gás natural liquefeito. Através das curvas do monitoramento do potencial de circuito aberto (OCP - Open Circuit Potential), das curvas de polarização linear anódica e das análises dos produtos de corrosão após a realização dos ensaios foi possível determinar qual das ligas apresentou melhor comportamento frente aos efeitos corrosivos impostos pelo meio utilizado.

No estudo de corrosão realizado em solução de água de mar sintética, as amostras do aço $9 \%$ Níquel com vários tratamentos térmicos apresentaram potenciais de corrosão com resultados similares para todas as condições de tratamentos e foi indicado na polarização anódica um comportamento de dissolução ativa, o que foi evidenciado pelo aumento contínuo da corrente até altas densidades [5]. Recentemente estão sendo desenvolvidos aços com teores acima de $15 \%$ de Manganês para aplicações de baixa permeabilidade magnética, resistência e tenacidade a baixas temperaturas (criogênicas) com a finalidade de serem utilizadas em equipamentos de transporte e armazenamento de gás natural liquefeito. Atualmente, está sendo realizadas pesquisas sobre a resistência a corrosão de aços alto Manganês com diferentes composições para usos criogênicos que serão usados 
em ambientes marinhos [4]. Há alguns trabalhos sobre o comportamento de polarização eletroquímica de ligas Fe-Mn. Os autores reportaram que estes aços não passivam em soluções aquosas de $3,5 \% \mathrm{NaCl}, 10 \%$ de $\mathrm{HCl}$ ou $10 \%$ de $\mathrm{HNO}_{3} \mathrm{e}$ que são susceptíveis a corrosão por pites, mas isso vai depender dos elementos de liga e suas quantidades [6]. Foi reportado também que o incremento do conteúdo de manganês acima de $25 \%$ diminui a resistência à corrosão da liga em soluções aquosas [7]. Foi citado que a adição de alumínio a uma liga com 25\% de Manganês teve como resultado o aumento da resistência à corrosão em soluções $1 \mathrm{M}$ de $\mathrm{Na}_{2} \mathrm{SO}_{4}, 50 \%$ de $\mathrm{HNO}_{3}$ e $10-50 \%$ de $\mathrm{NaOH}$, mas que em soluções de $10 \%$ de $\mathrm{HCl}$ e $\mathrm{NaCl} 3,5 \%$ este mesmo aço não apresentou passivação [8].

\section{MATERIAIS E MÉTODOS}

Os materiais foram fornecidos pelo Laboratório de Caracterização de Materiais (LACAM) da Universidade Federal do Ceará (UFC). As amostras dos aços alto Manganês foram laminadas com $80 \%$ de redução na espessura e tratadas termicamente a $1150^{\circ} \mathrm{C}$ e solubilizadas em água. As amostras do aço $9 \%$ Níquel também passaram pelo mesmo processo. A composição dos aços $22 \%$ Manganês, 27\% Manganês e 9\% Níquel são mostradas nas Tabelas 1, 2, e 3 respectivamente.

Tabela 1. Composição Química da liga de aço 22\% Manganês [\%p]

\begin{tabular}{c|c|c|c|c|c|c|c}
\hline Mn & Si & Al & C & Cr & Ni & Cu & Fe \\
\hline 22,22 & 2,51 & 3,39 & 0,53 & 0,48 & 0,26 & 0,2 & Bal. \\
\hline \multicolumn{6}{c}{ Fonte: Autor. }
\end{tabular}

Tabela 2. Composição Química da liga de aço 27\% Manganês [\%p]

\begin{tabular}{c|c|c|c|c|c}
\hline Mn & $\mathbf{S i}$ & $\mathbf{C}$ & $\mathbf{C r}$ & $\mathbf{~ N i}$ & $\mathbf{F e}$ \\
\hline 27 & 1,0 & 0,027 & 0,40 & 0,19 & Bal. \\
\hline \multicolumn{6}{c}{ Fonte: Autor. }
\end{tabular}

Tabela 3. Composição Química da liga de aço 9\% Níquel [\%p]

\begin{tabular}{c|c|c|c|c|c|c}
\hline $\mathbf{N i}$ & $\mathbf{M n}$ & $\mathbf{S i}$ & $\mathbf{C}$ & $\mathbf{C r}$ & $\mathbf{V}$ & $\mathbf{F e}$ \\
\hline 8,65 & 0,65 & 0,25 & 0,09 & 0,1 & 0,11 & Bal. \\
\hline \multicolumn{6}{c}{ Fonte: Autor. }
\end{tabular}

As medidas eletroquímicas foram feitas no Laboratório de Pesquisa em Corrosão (LPC) da Universidade Federal do Ceará (UFC), utilizando o potenciostato/galvanostato Autolab PGSTAT 302N da Metrohm ${ }^{\circledR}$, controlado pelo programa NOVA ${ }^{\circledR}$ V1.11 para aquisição e tratamento dos dados. Foi utilizada uma célula convencional de três eletrodos o de referência, de trabalho e o contra eletrodo. Onde o eletrodo de referência foi utilizado o $\mathrm{Ag}(\mathrm{s}) / \mathrm{AgCl}(\mathrm{s}) / \mathrm{Cl}^{-}(\mathrm{aq})$ ( $\mathrm{KCL}$ saturado), o contra eletrodo é feito com uma placa de platina com área geométrica retangular de $130 \mathrm{~mm}^{2}$ aproximadamente, e os eletrodos de trabalho foram feitos com as amostras de cada um dos aços com área aproximada de $30 \mathrm{~mm}^{2}$. Para a montagem dos eletrodos de trabalho, foram cortadas três amostras retangulares de cada um dos aços, depois foram fixadas a cada amostra um fio de cobre, e esse conjunto foi colocado no interior de um segmento de tubo de PVC para realização do embutimento a frio em resina epóxi. Antes da realização das medidas eletroquímicas, os corpos de prova foram lixados com lixas de carbeto de silício (SiC) com granulação 100, 220, 340, 400, 600 e 1200 seguido de lavagem com água 
destilada, de lavagem com etanol para desengordurar e finalmente foi utilizado um e jato de ar quente para secar a superfície das amostras. As medidas foram feitas na temperatura ambiente, os ensaios de OCP foram realizados pela imersão do eletrodo de trabalho na solução durante 1 hora. As curvas de polarização linear anódica foram obtidas em uma faixa de potencial de $+300 \mathrm{mV}$ em torno do potencial de circuito aberto e a velocidade de varredura utilizada foi de $1 \mathrm{mV} / \mathrm{s}$. A Figura 1 mostra a montagem dos equipamentos (computador, potenciostato, célula eletroquímica) que normalmente são usadas para fazer os ensaios de corrosão mencionados anteriormente.

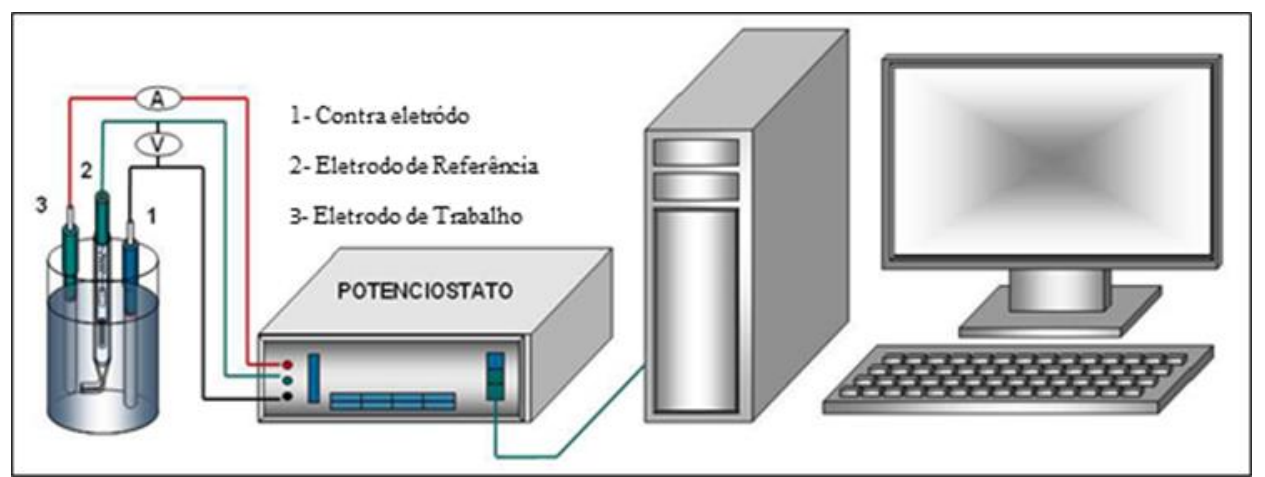

Figura 1. Montagem dos equipamentos a serem empregados nos ensaio eletroquímicos. Fonte: [9].

Microscópio ótico Zeiss modelo (Axio Imager 2) foi utilizado na aquisição das imagens microscópicas. Equipamento este presente no Laboratório de Caracterização de Materiais (LACAM-UFC). Também para analisar os detalhes da morfologia dos produtos de corrosão foram realizadas as aquisições de imagens no MEV TESCAN ${ }^{\circledR}$ modelo VEGA XMU do Instituto de Pesquisas, Desenvolvimento e Inovação do Governo do Estado do Ceará (IPDI). No mesmo equipamento também foram realizadas medidas de Espectroscopia de Dispersão de Energia de Raios $X$ (EDS) utilizando o software Esprit 1.8 para geração dos espectros de difração e quantificação dos elementos químicos presentes nos produtos de corrosão.

\section{RESULTADOS E DISCUSSÃO}

\subsection{Ensaios de Corrosão}

Inicialmente foram feitas medidas de OCP e polarização linear anódica em solução $0,1 \mathrm{M}$ e $0,01 \mathrm{M}$ de $\mathrm{NaCl}$, tendo como resultados curvas que não mostraram ser agressivas para os aços, por tanto foi utilizada uma concentração $0,001 \mathrm{M}$ de $\mathrm{NaCl}$ onde foram obtidas as curvas esperadas, similares às encontradas na literatura. Uma vez definida a concentração da solução em $0,001 \mathrm{M}$ de $\mathrm{NaCl}$ foram realizados os ensaios das ligas como indicado na seção de materiais e métodos, e foram feitas medidas do $\mathrm{pH}$ da solução antes e depois do ensaio no equipamento TECNAL Tec-5 disponível Laboratório de Pesquisa em Corrosão (LPC). Na Figura 2 podemos observar os resultados do ensaio de OCP e na Figura 3 podemos ver os resultados dos ensaios de polarização linear anódica. 


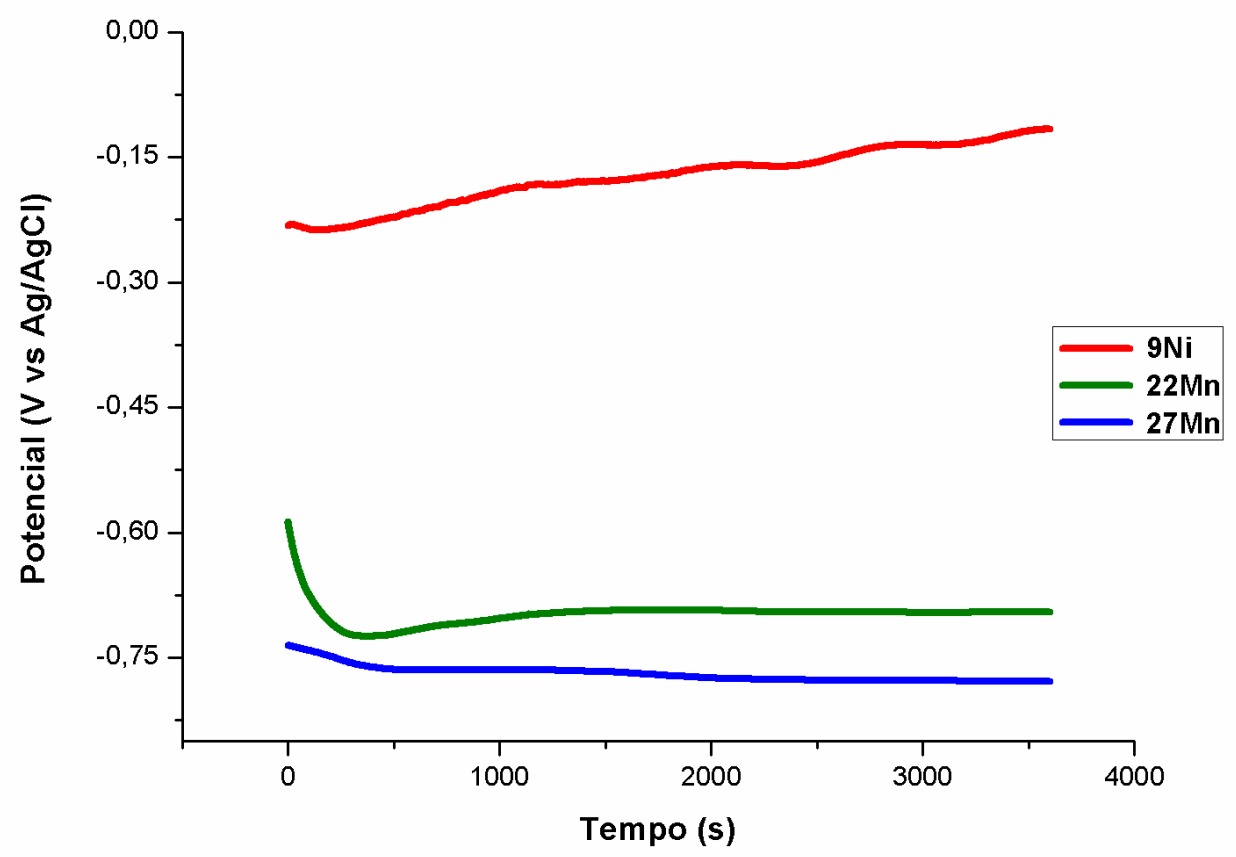

Figura 2. Curvas de OCP do aço $9 \%$ Níquel e os aços alto Manganês em solução 0,001M de $\mathrm{NaCl}$. Fonte: Autor.

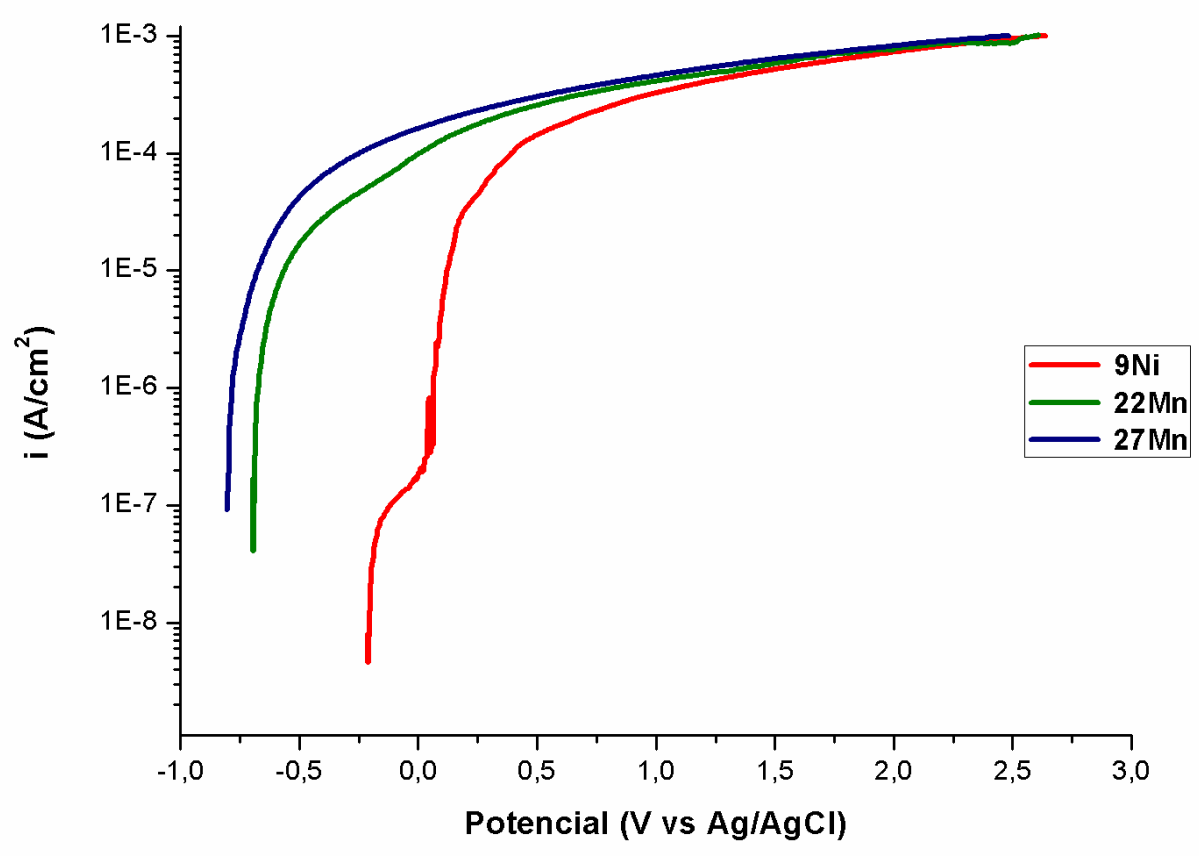

Figura 3. Polarização Linear Anódica do aço $9 \%$ Níquel e os aços alto Manganês em solução $0,001 \mathrm{M}$ de $\mathrm{NaCl}$.

Fonte: Autor.

De acordo com as curvas de OCP (Figura 2) e de Polarização Linear Anódica (Figura 3), pode-se dizer que o aço $9 \%$ Níquel apresentou um comportamento mais nobre do que os aços alto Manganês, isso foi constatado com a medição do 
potencial de corrosão ( $E_{\text {corr }}$ onde o aço $9 \%$ Níquel mostrou um valor menos negativo, o que evidencia uma melhor resistência à corrosão do que os outros aços, como se pode observar na Tabela 4. Também foi observado que nenhum dos aços apresentou comportamento de passivação, isso é um indicativo da baixa resistência à corrosão neste meio, tal como foi mencionado por [6].

Tabela 4. Potenciais de Corrosão ( $E_{\text {corr }}$ dos aços em solução $0,001 \mathrm{M}$ de $\mathrm{NaCl}$

\begin{tabular}{ccc}
\hline \multicolumn{3}{c}{ Potencial de Corrosão $\mathbf{E}_{\text {corr }}(\mathbf{V})$} \\
\hline $9 \%$ Níquel & $22 \%$ Manganês & $27 \%$ Manganês \\
$-0,213$ & $-0,694$ & $-0,805$ \\
\hline
\end{tabular}

Fonte: Autor.

\subsection{Analises dos Produtos de Corrosão}

A varredura durante os ensaios de polarização linear anódica foi encerrada quando a corrente atingiu $1 \mathrm{~mA}$, a fim de para garantir a integridade da amostra, com isso foi possível a caracterização da superfície após os ensaios através das técnicas de MEV e EDS para a obtenção de imagens e composição dos produtos de corrosão. $\mathrm{Na}$ Figura 4 se pode observar uma imagem obtida por microscopia eletrônica de varredura com aumento de 100X da amostra do aço $9 \%$ Níquel após os ensaios de polarização linear anódica. Na imagem é possível observar a superfície da amostra com marcas do lixamento, grande presença de pites em diversos pontos, marcas onde parece ter uma forte dissolução do aço e formações irregulares em diversos pontos da superfície da amostra. Ao lado da Figura 4 temos o resultado da medição feita por EDS dos produtos de corrosão do aço $9 \%$ de Níquel, onde foi observada sua composição através dos picos dos elementos $\mathrm{Fe}, \mathrm{Ni}, \mathrm{Si}, \mathrm{Mn}$ e $\mathrm{S}$. A Tabela 5 mostra a quantificação das medidas feitas na análise EDS dos produtos de corrosão mencionados anteriormente. Pode-se afirmar então, que o aço tem facilidade de reagir com o eletrólito formando óxidos e sulfetos com os elementos de liga que seriam dissolvidos durante a polarização, tais como $\mathrm{Fe}, \mathrm{Ni}, \mathrm{Mn}$ e Si como pode ser observado nos resultados da análise EDS.

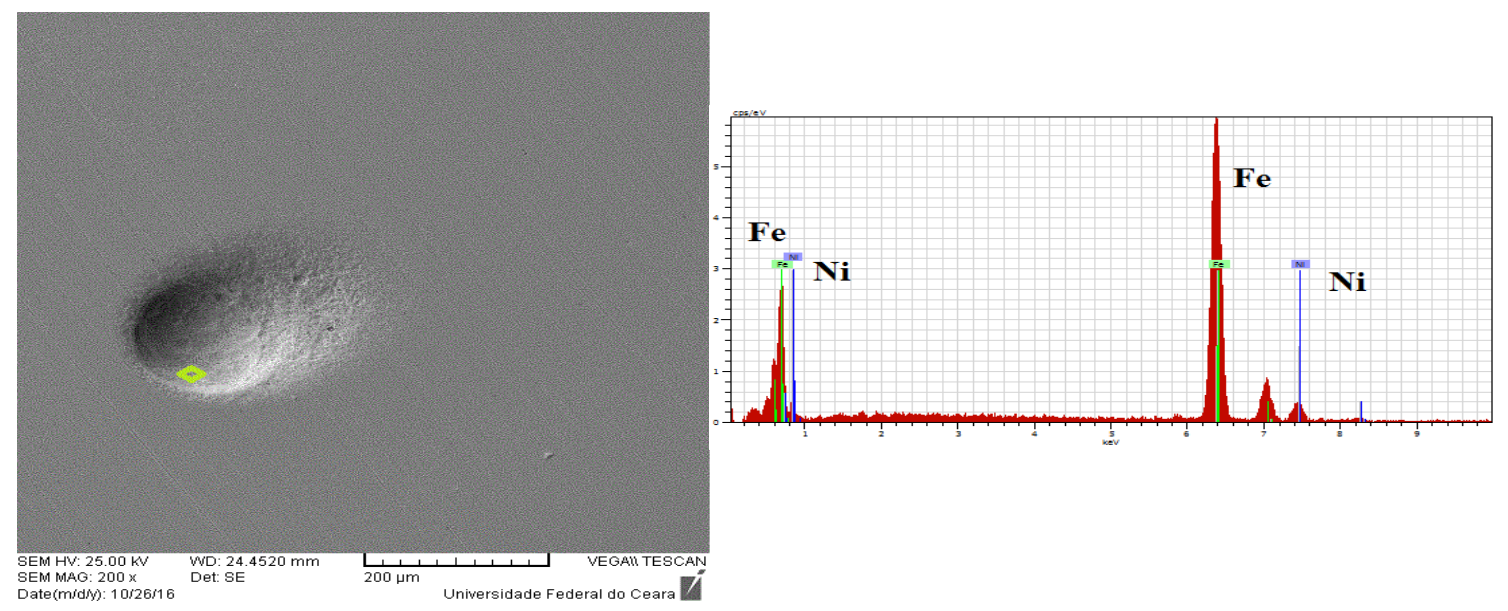

Figura 4. Micrografía eletrônica de varredura a 200X do aço $9 \%$ Níquel. Difratograma obtido no EDS. Fonte: Autor. 
Tabela 5. Resultado do EDS quantificado por elementos dos produtos de corrosão da liga de aço $9 \%$ Níquel em solução 0,001M de $\mathrm{NaCl}$

\begin{tabular}{|c|c|c|c|c|c|c|}
\hline \multicolumn{7}{|c|}{ Composição do espectro de Aquisição: } \\
\hline El & AN & Series & Unn. [\%p] & C Norm. [\%p] & C Atom. [at.\%p] & C Erro [\%] \\
\hline $\mathrm{Fe}$ & 26 & K - series & 85,17 & 90,64 & 91,05 & 2,3 \\
\hline $\mathrm{Ni}$ & 28 & $\mathrm{~K}$ - series & 8,80 & 9,36 & 8,95 & 0,4 \\
\hline \multicolumn{3}{|c|}{ Total } & 93,97 & 100,00 & 100,00 & \\
\hline
\end{tabular}

Pelas imagens podemos dizer que o aço não apresenta boa resistência à corrosão devido a que a camada de produtos de corrosão (óxidos) apresenta trincas e porosidade, isso não proporciona proteção frente ao ataque da solução. Também é importante destacar que foi feita uma revisão dos diagramas de Pourbaix [9] levando em consideração os potenciais medidos e o pH da solução, com isso foi estudada a afinidade dos elementos $\mathrm{Fe}, \mathrm{Mn}, \mathrm{Ni}$ e $\mathrm{Si}$ em formar óxidos em soluções aquosas com pH aproximado de 3,5.

Na Figura 5 podemos observar uma imagem obtida por MEV da amostra do aço $27 \%$ Manganês com aumento de $100 \mathrm{X}$ após os ensaios de polarização linear anódica, na imagem podemos observar marcas de lixamento, a formação de uma camada de produtos de corrosão com trincas que cobrem toda a superfície da amostra, e a formação de nódulos de produtos de corrosão em certos locais isolados com diferentes tamanhos. Ao lado da Figura 5 é apresentado o resultado da medição feita por EDS dos produtos de corrosão do aço 22\% Manganês, onde podemos observar a composição destes produtos de corrosão através dos picos dos elementos $\mathrm{Fe}, \mathrm{Mn}, \mathrm{Al}, \mathrm{Si}, \mathrm{O}$ e S. A Tabela 6 mostra a quantificação das medidas feitas na análise EDS dos produtos de corrosão mencionados anteriormente. Analisando as imagens, os resultados da análise EDS e os diagramas de Pourbaix dos elementos do aço, podemos afirmar que este aço apresenta baixa resistência à corrosão devido a afinidade dos elementos do aço em formar óxidos e sulfetos com os íons da solução $0,001 \mathrm{M}$ de $\mathrm{H}_{2} \mathrm{SO}_{4}$, estes óxidos e sulfetos formam uma camada na superfície da amostra que não oferece uma boa proteção pois ela não é compacta e apresenta trincas que permitem a entrada dos íons no substrato metálico, continuando assim o processo de dissolução do aço, como foi descrito também por [10] e por [7].

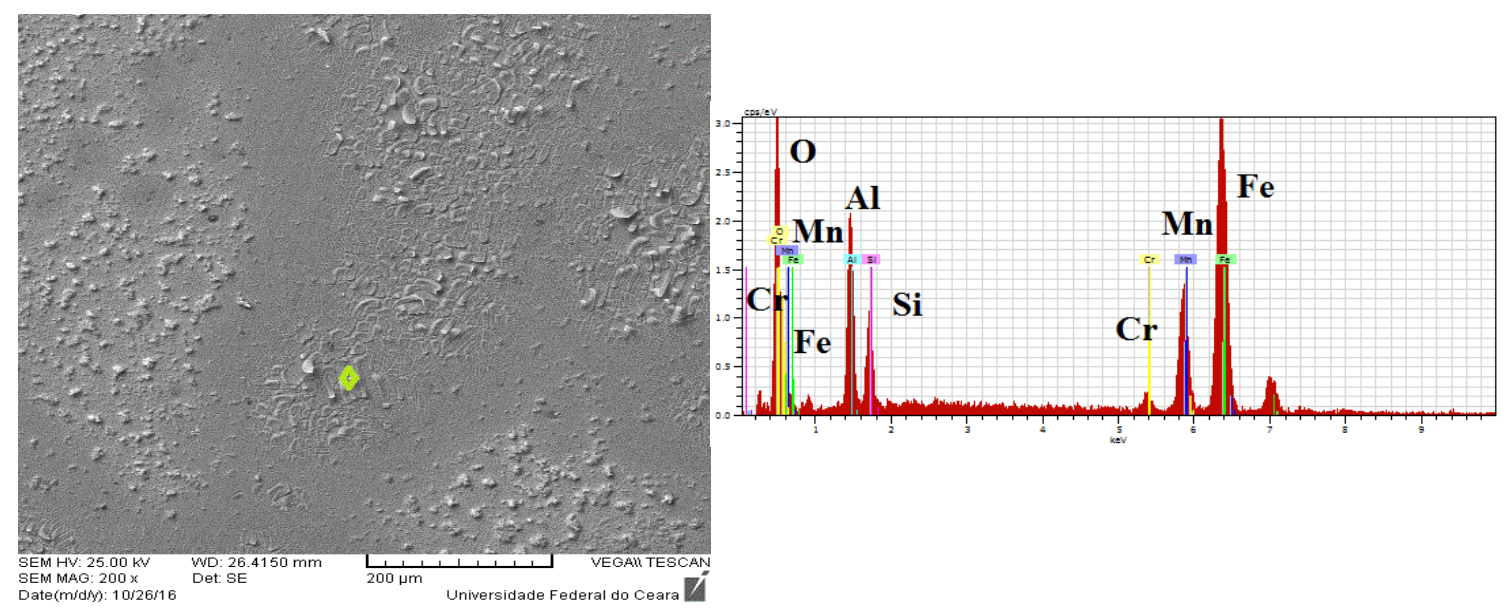

Figura 5. Micrografía eletrônica de varredura a 100X do aço 22\% Manganês. Difratograma obtido no EDS. Fonte: Autor. 
Tabela 6. EDS quantificado por elementos dos produtos de corrosão do aço $22 \%$ Manganês em solução $0,001 \mathrm{M}$ de $\mathrm{NaCl}$.

\begin{tabular}{|c|c|c|c|c|c|c|}
\hline \multicolumn{7}{|c|}{ Espectro de Aquisição: } \\
\hline El & AN & Series & Unn. [\%p] & C Norm. [\%p] & C Atom. [at.\%p] & C Erro [\%] \\
\hline $\mathrm{O}$ & 8 & $\mathrm{~K}$ - series & 17,98 & 18,61 & 39,63 & 4,7 \\
\hline $\mathrm{Al}$ & 13 & $\mathrm{~K}$ - series & 11,81 & 12,22 & 15,43 & 0,7 \\
\hline $\mathrm{Si}$ & 14 & $\mathrm{~K}$ - series & 4,05 & 4,19 & 5,08 & 0,2 \\
\hline $\mathrm{Cr}$ & 24 & $\mathrm{~K}$ - series & 1,41 & 1,46 & 0,95 & 0,2 \\
\hline Mn & 25 & $\mathrm{~K}$ - series & 14,41 & 14,92 & 9,25 & 0,6 \\
\hline $\mathrm{Fe}$ & 26 & $\mathrm{~K}$ - series & 46,95 & 48,60 & 29,65 & 1,3 \\
\hline \multicolumn{3}{|c|}{ Total } & 96,60 & 100,00 & 100,00 & \\
\hline
\end{tabular}

Fonte: Autor.

Na Figura 6 podemos observar uma imagem obtida por microscopia eletrônica de varredura a 100X da amostra do aço $27 \%$ Manganês após os ensaios de polarização linear anódica. Na imagem é possível observar a superfície da amostra onde se pode ver a formação de uma camada em toda a superfície e a formação de estruturas ou nódulos de formas irregulares em diversos pontos da superfície da amostra. Ao lado da Figura 6 é apresentado o resultado da medição feita por EDS dos produtos de corrosão do aço $27 \%$ Manganês, onde podemos observar a composição dos produtos de corrosão através dos picos dos elementos $\mathrm{Fe}, \mathrm{Mn}, \mathrm{Al}$, $\mathrm{Si}$, O e S. A Tabela 7 mostra a quantificação das medidas feitas na análise EDS dos produtos de corrosão mencionados anteriormente. Analisando as imagens, os resultados do EDS e os diagramas de Pourbaix dos elementos do aço podemos afirmar que esse aço apresenta baixa resistência à corrosão devido a afinidade que os elementos de liga tem em formar principalmente óxidos e sulfetos com os íons da solução $0,001 \mathrm{M}$ de $\mathrm{H}_{2} \mathrm{SO}_{4}$, estes óxidos e sulfetos formam uma camada na superfície da amostra que não oferece uma boa proteção contra a corrosão devido ao fato de que esta não é compacta e apresenta trincas que permitem a entrada dos íons, acelerando o processo de dissolução da liga, semelhante ao que ocorreu com o aço $22 \%$ Manganês, como foi descrito por.
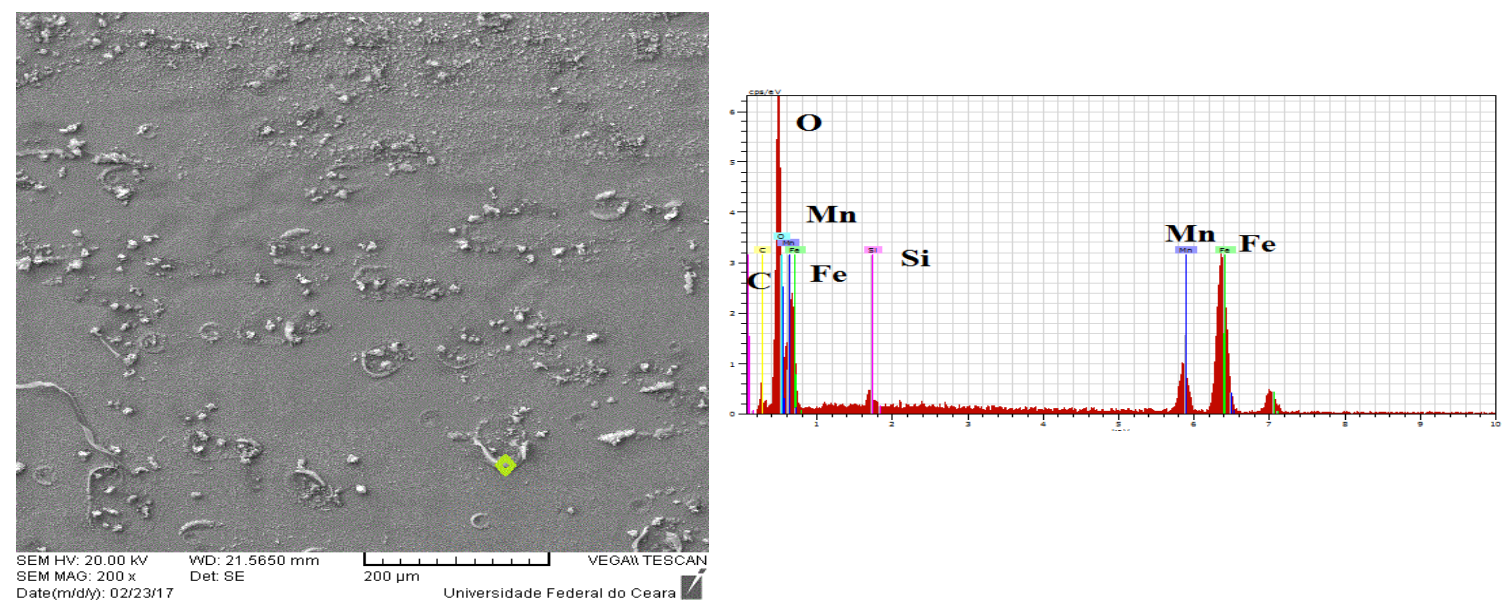

Figura 6. Micrografía eletrônica de varredura a 200X do aço 28\% Manganês. Fonte: Autor. 
Tabela 7. EDS quantificado por elementos dos produtos de corrosão da liga de aço $27 \%$ Manganês em solução 0,001M de $\mathrm{NaCl}$.

\begin{tabular}{|c|c|c|c|c|c|c|}
\hline \multicolumn{7}{|c|}{ Espectro de Aquisição: } \\
\hline$\overline{E l}$ & $\overline{\text { AN }}$ & Series & Unn. [\%p] & C Norm. [\%p] & C Atom. [at.\%p] & C Erro [\%] \\
\hline O & 8 & $\mathrm{~K}$ - series & 21,06 & 21,45 & 49,22 & 3,7 \\
\hline $\mathrm{Si}$ & 14 & $\mathrm{~K}$ - series & 0,96 & 0,93 & 1,83 & 0,1 \\
\hline $\mathrm{Mn}$ & 25 & $\mathrm{~K}$ - series & 23,96 & 23,36 & 23,44 & 0,9 \\
\hline $\mathrm{Fe}$ & 26 & $\mathrm{~K}$ - series & 52,57 & 54,26 & 25,51 & 2,3 \\
\hline \multicolumn{3}{|c|}{ Total } & 98,55 & 100,00 & 100,00 & \\
\hline
\end{tabular}

\section{CONCLUSÃO}

A análise comparativa dos resultados dos ensaios de corrosão dos aços estudados em solução $0,001 \mathrm{M}$ de $\mathrm{NaCl}$ mostrou que ainda apresentando corrosão por pites e dissolução do material, o aço $9 \%$ Níquel possui uma melhor resistência à corrosão do que os aços $22 \%$ e $27 \%$ Manganês. As ligas de aço alto Manganês apresentaram um desempenho inferior, possivelmente pela presença de maior quantidade de elementos da liga que tem a afinidade de formar óxidos quando estão em soluções aquosas. Podemos afirmar também que o aumento de teor de Manganês reduziu consideravelmente a resistência à corrosão dos aços alto $\mathrm{Mn}$. A camada formada na superfície não oferece proteção, devido à presença de trincas e elevada porosidade, que permite os íons da solução irem até a superfície do metal, acelerando o processo de dissolução da liga. Foi observado também que a liga com teor de $22 \%$ de $\mathrm{Mn}$ apresentou uma leve melhoria na resistência à corrosão do que a liga com $27 \%$ de Manganês, isso pode ser associado a que a liga de aço $22 \%$ Mn possui uma porcentagem de alumínio, este elemento forma óxidos mais estáveis do que os de Ferro e o Manganês.

Também é importante mencionar que a diferença na resistência a corrosão que existe entre estes aços alto manganês e o aço $9 \%$ níquel, pode ser minimizada pelas condições de temperaturas criogênicas onde são utilizados normalmente estes aços; assim, se espera que na medida em que a temperatura diminua a concentração de oxigênio disponível para reagir com os aços diminua. Também podemos acrescentar que a parte externa pode receber uma cobertura química para a proteção do material de base, além do custo beneficio em ralação ao $9 \%$ Níquel. Por tanto, dadas as excelentes propriedades mecânicas mencionadas na literatura além do melhor custo beneficio em relação ao aço $9 \%$ Níquel, os aços alto Manganês podem ser uma alternativa muito boa para substituir os materiais utilizados pela indústria de armazenamento e transporte de gás natural liquefeito.

\section{Agradecimentos}

Este trabalho foi apoiado pela Fundação de Apoio ao Desenvolvimento Científico e Tecnológico (FUNCAP) do Estado do Ceará, assim como do Laboratório de Pesquisa em Corrosão e do Laboratório de Caracterização de Materiais da Universidade Federal do Ceará. 


\section{REFERÊNCIAS}

1 LIMA, M.N.S., Caracterização e propriedades mecânicas dos aços com alto teor de manganês (18-28\%p) e carbono (1,1-1,7\%p) produzidos em um forno de indução no laboratório de fundição da Universidade Federal do Ceará. Trabalho de Conclusão de Curso. Graduação em Engenharia Metalúrgica e de Materiais. Universidade Federal do Ceará. Fortaleza - CE, 2016.

2 LIMA, G. R. Influência dos elementos de liga no encruamento proveniente do processo de usinagem nos aços Hadfield, em III Seminário da Pós-Graduação em Engenharia Mecânica. Unesp. Bauru, São Paulo. 2009.

3 AVERY. Howard. S. Austenitic Manganese Steel, ASM Handbook, v.1, p.1274 - 1283, 2004.

4 CHOI, J. K. High Manganese Austenitic Steel for Cryogenic Applications. In: The Twentysecond (2012) International Offshore and Polar Engineering Conference, by the International Society of Offshore and Polar Engineers (ISOPE), Grecia, 2012.

5 DE SÁ, J. Estudo de Resistência a Corrosão e Fragilização por Hidrogênio em Aço 9\% Ni. (Monografia). Escola Politécnica, Universidade Federal do Rio de Janeiro, 2015.

6 HAMADA, A. S. Effect of Anodic Passivation on the Corrosion Behaviour of Fe-Mn-Al Steels in 3.5\% NaCl. Passivation of Metals and Semiconductors, and Properties of Thin Oxide Layers, Paper No. 77 of the $9^{\text {th }}$ International Symposium, France, 2006.

7 ZHANG, Y. S; ZHU, X. M; LIU, M; CHE, R. X. Effects of Anodic Passivation on the Constitution, Stability and Resistance to Corrosion of Passive Film Formed on Fe-24mn-4al-5cr Alloy. Surface Science 222 (2004) 89-101, China, 2004.

8 HYUNG, S; JIN, H; JUN, Y; JONG, G; JEONG, K; KYOO, Y. Electrochemical Corrosion Property of High Mn Steel in Sweet Environment. POSTECH, POSCO Technical Research Laboratories. Twenty-fourth (2014) International Ocean and Polar Engineering Conference, Korea, 2014

9 MARTINEZ, D. Influencia de las Variables Hidrodinamicas Presion, Temperatura y Velocidad del Fluido en el Proceso de Corrosion del Acero al Carbono AISI 1020 en Presencia de $\mathrm{CO}_{2-}$ Agua-NaCl. (Monografia). Escuela de Ingenieria Quimica de la Universidad Industrial de Santander (UIS). Colombia, 2008.

10 TAKENO, N. Atlas of Eh-pH Diagrams. National Institute of Advanced Industrial Science and Technology. Intercomparison of thermodynamic databases, Geological Survey of Japan Open File Report No.419, 2005.

11 KANNAN, M B; Raman, R. K. S; KHODDAM, S. Comparative Studies on the Corrosion Properties of a Fe-Mn-Al-Si Steel and an Interstitial-Free Steel. Corrosion Science 50 (2008) 2879-2884, Australia, 2008. 